What is the PURPOSE of a COLLEGE LIBRARY?

Please write your answer on the whiteboard.

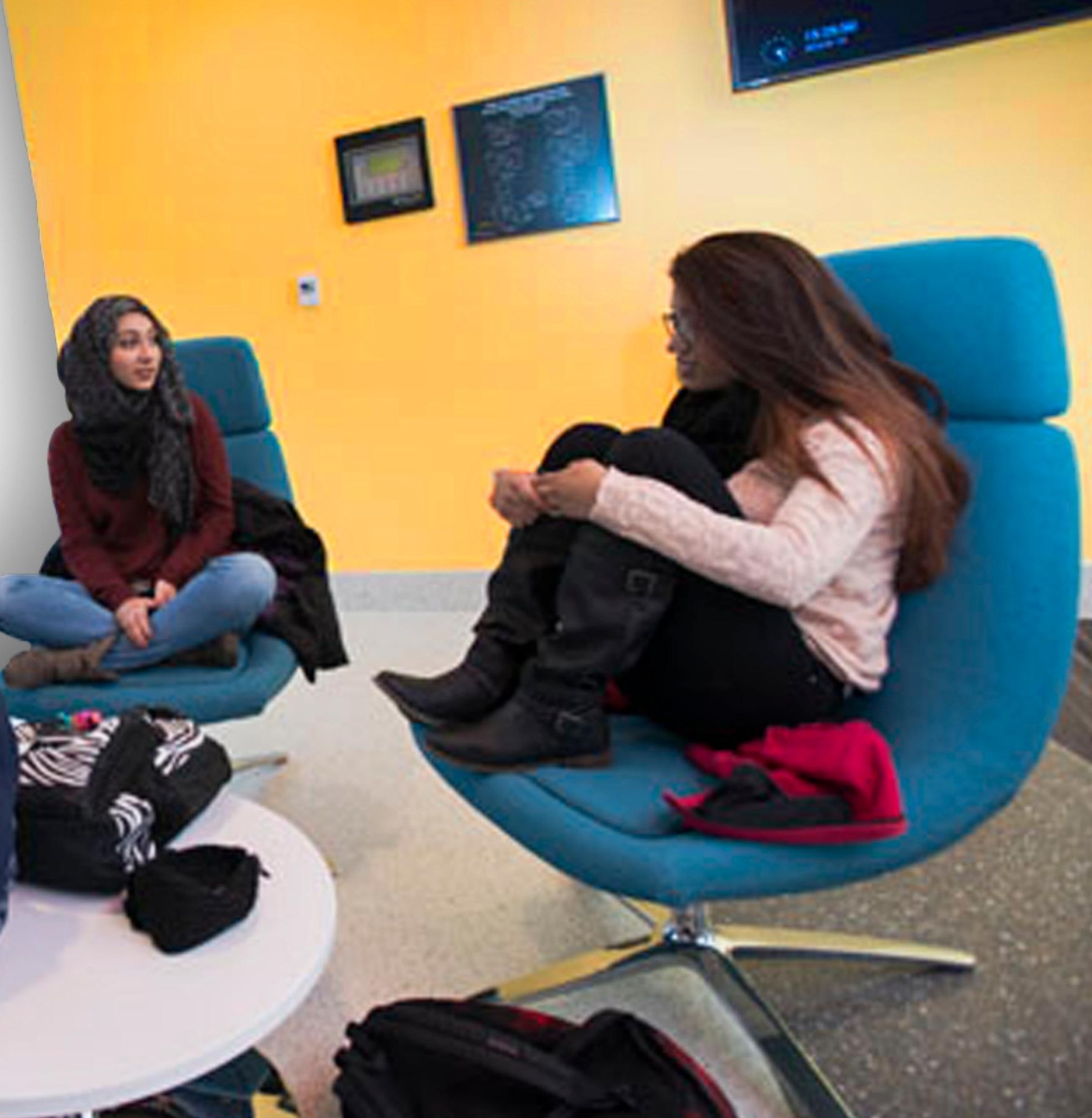




$$
\text { ZzZzZzZzZ }
$$

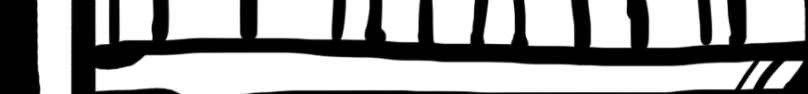

O ZzZzZzZzZ
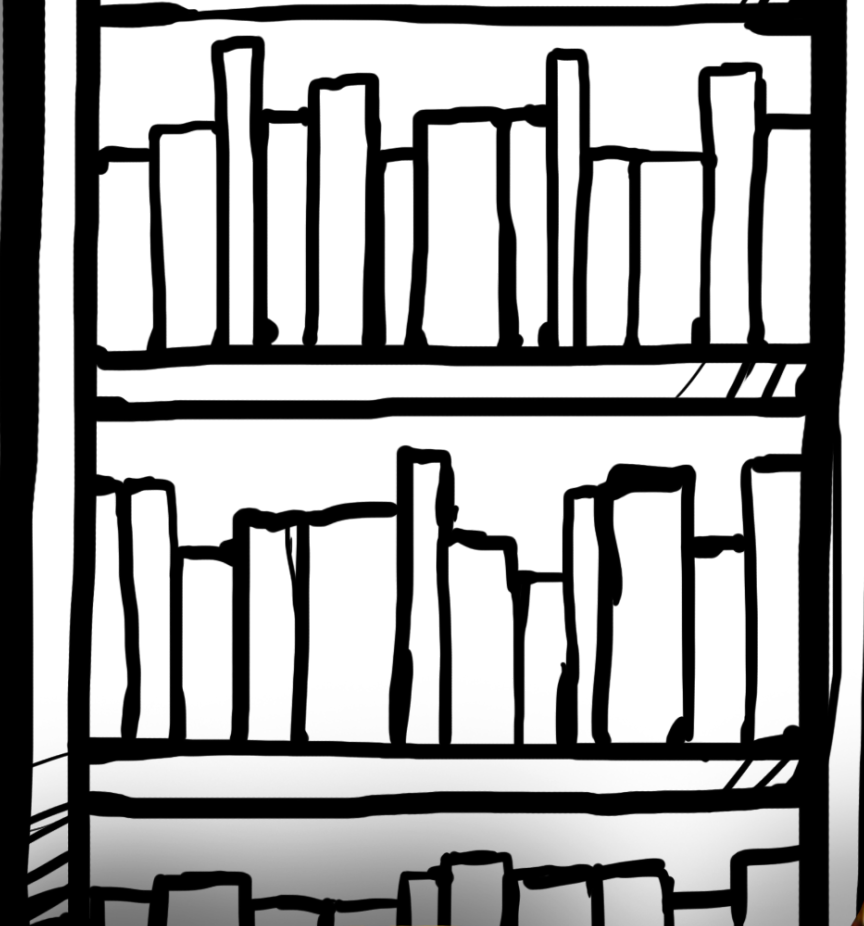

O
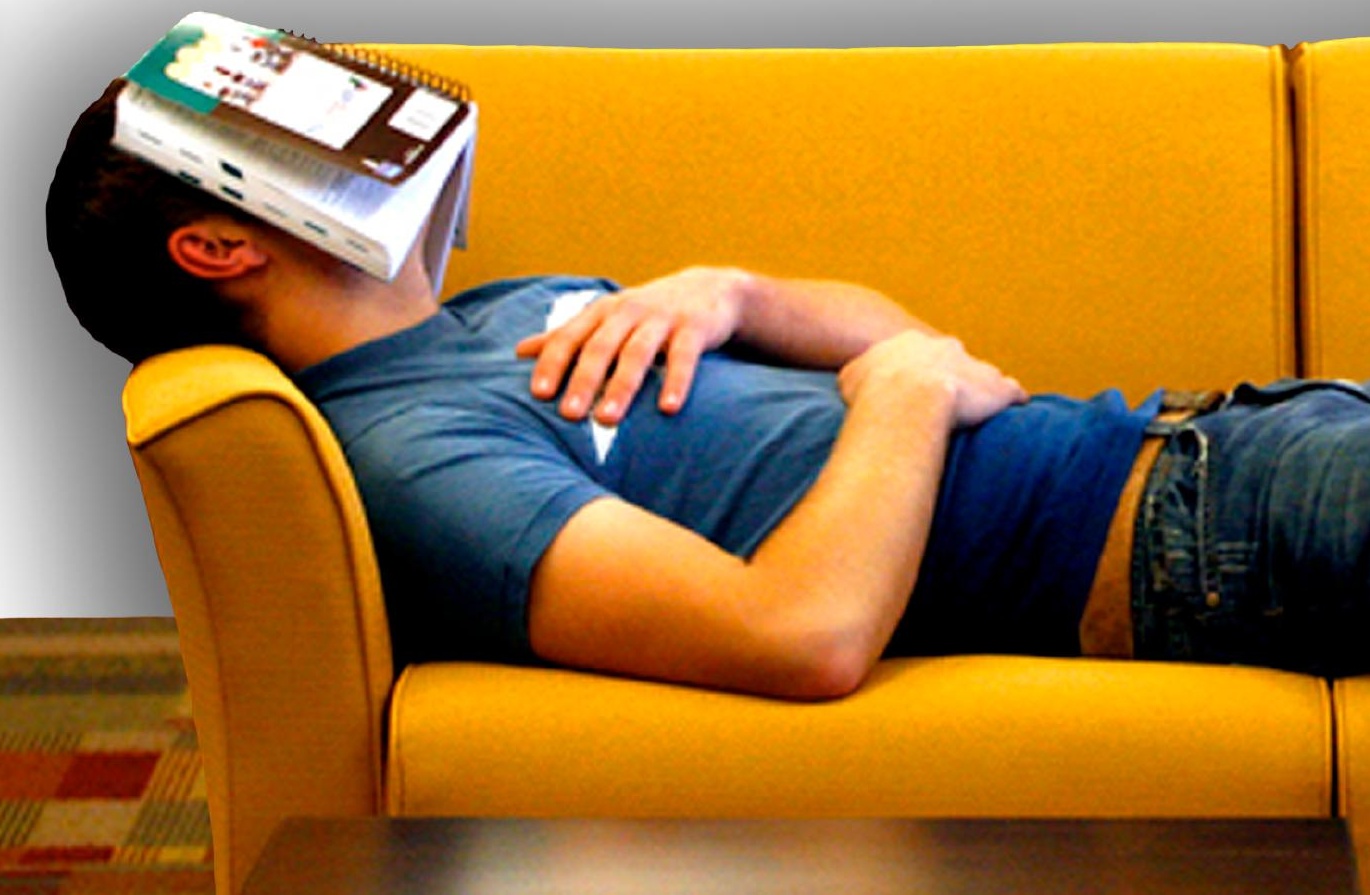


\section{LIBRARIAN-INSTRUCTOR PARTNERSHIPS:}

Empowering Students To Share Their

Research with the Community
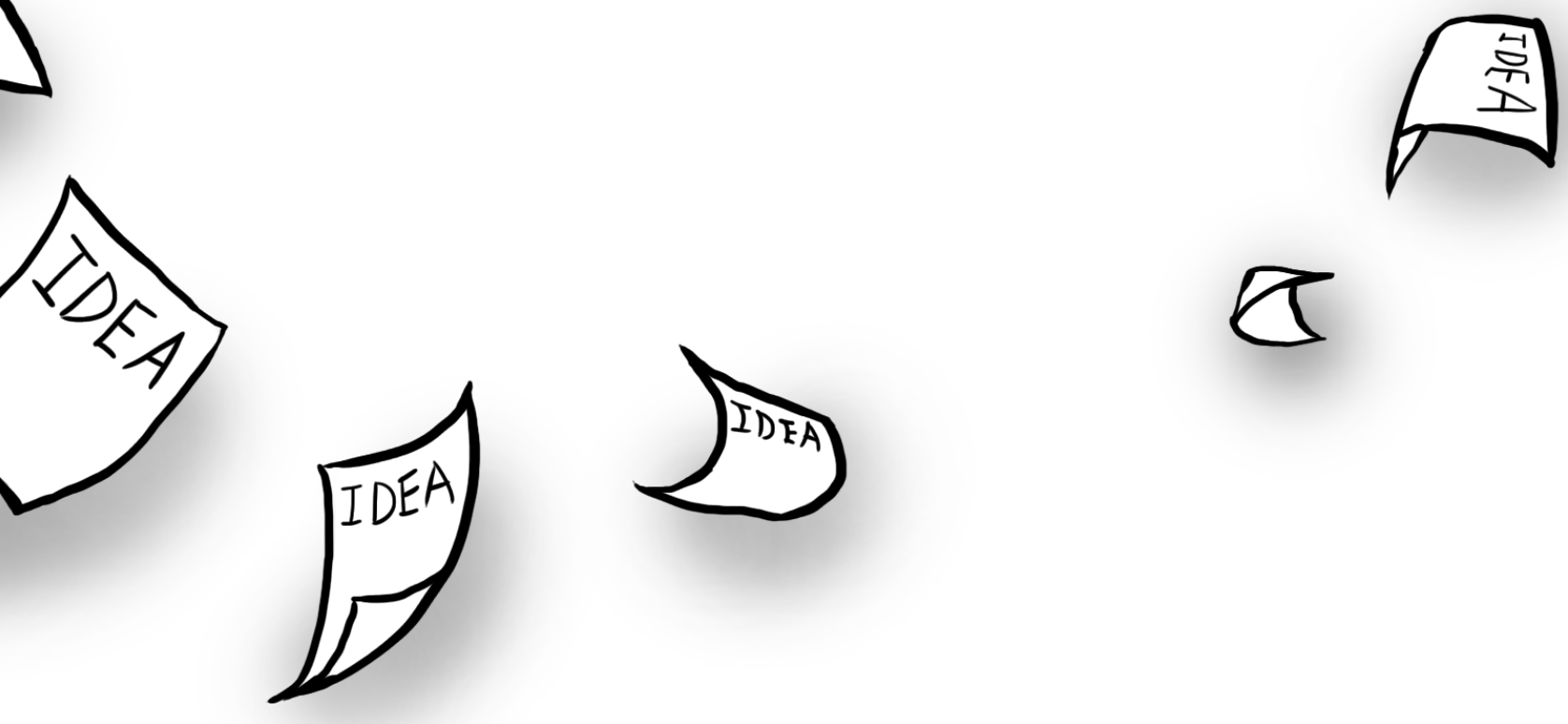

Prepared by Kerry Folan \& Maoria Kirker Graphic Design by Ye Sun Kim 

Instructor's Perspective

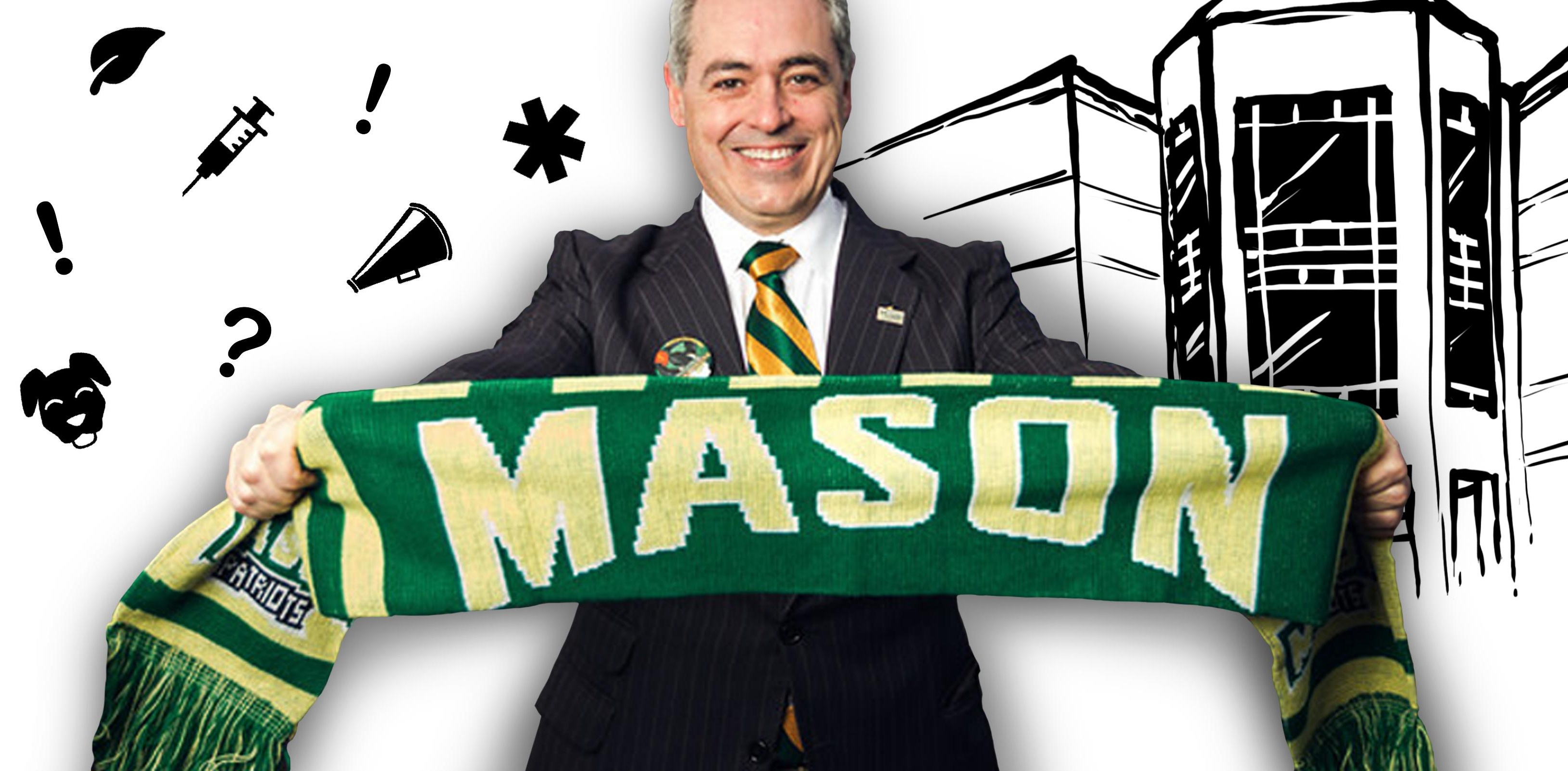




\section{Students' Perspective}

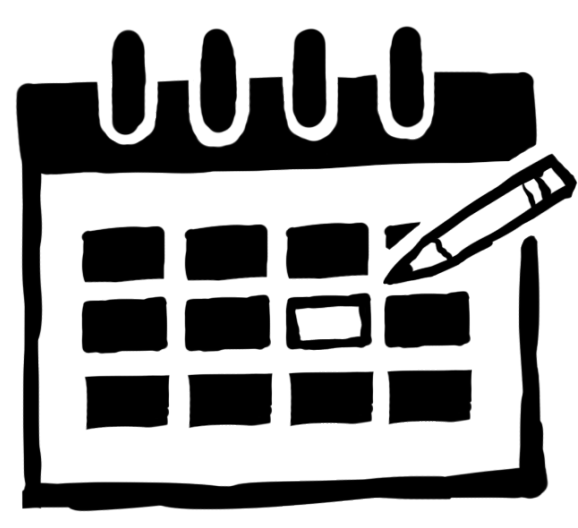

12 of 26 students

made an appointment in the fall

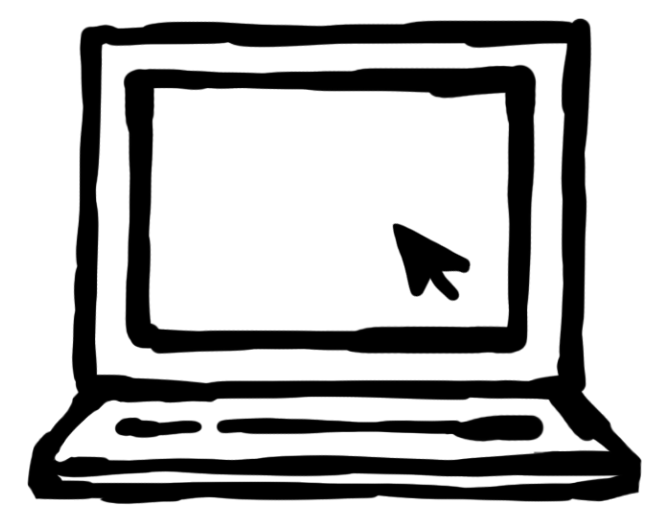

Most helpful skill:

Using databases

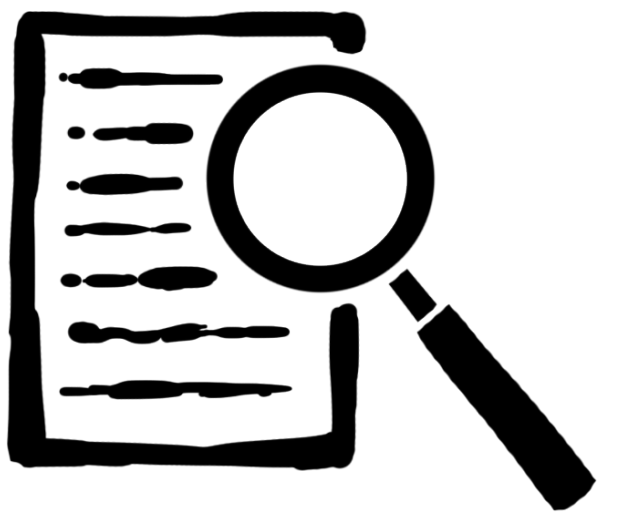

Students self-report research skills as 7 out of 10 in the spring

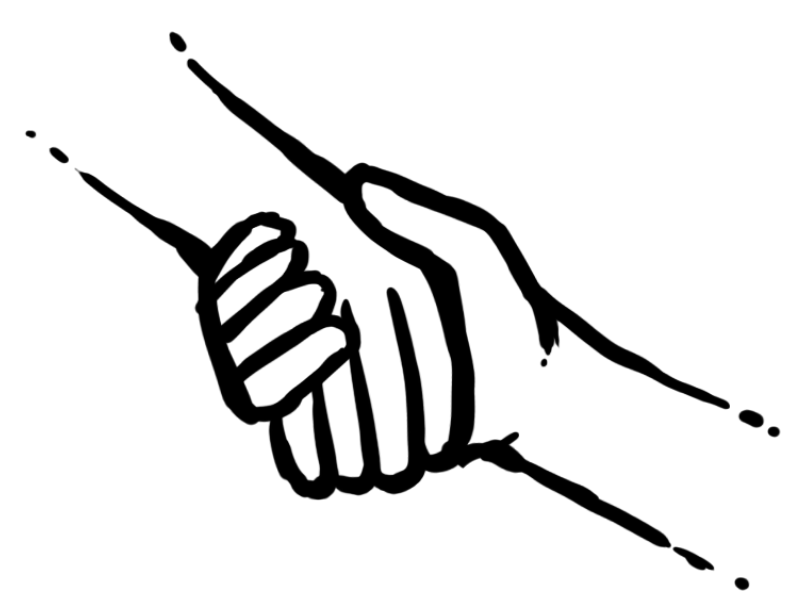

Helpfulness of the librarian/library 
Librarian's Perspective

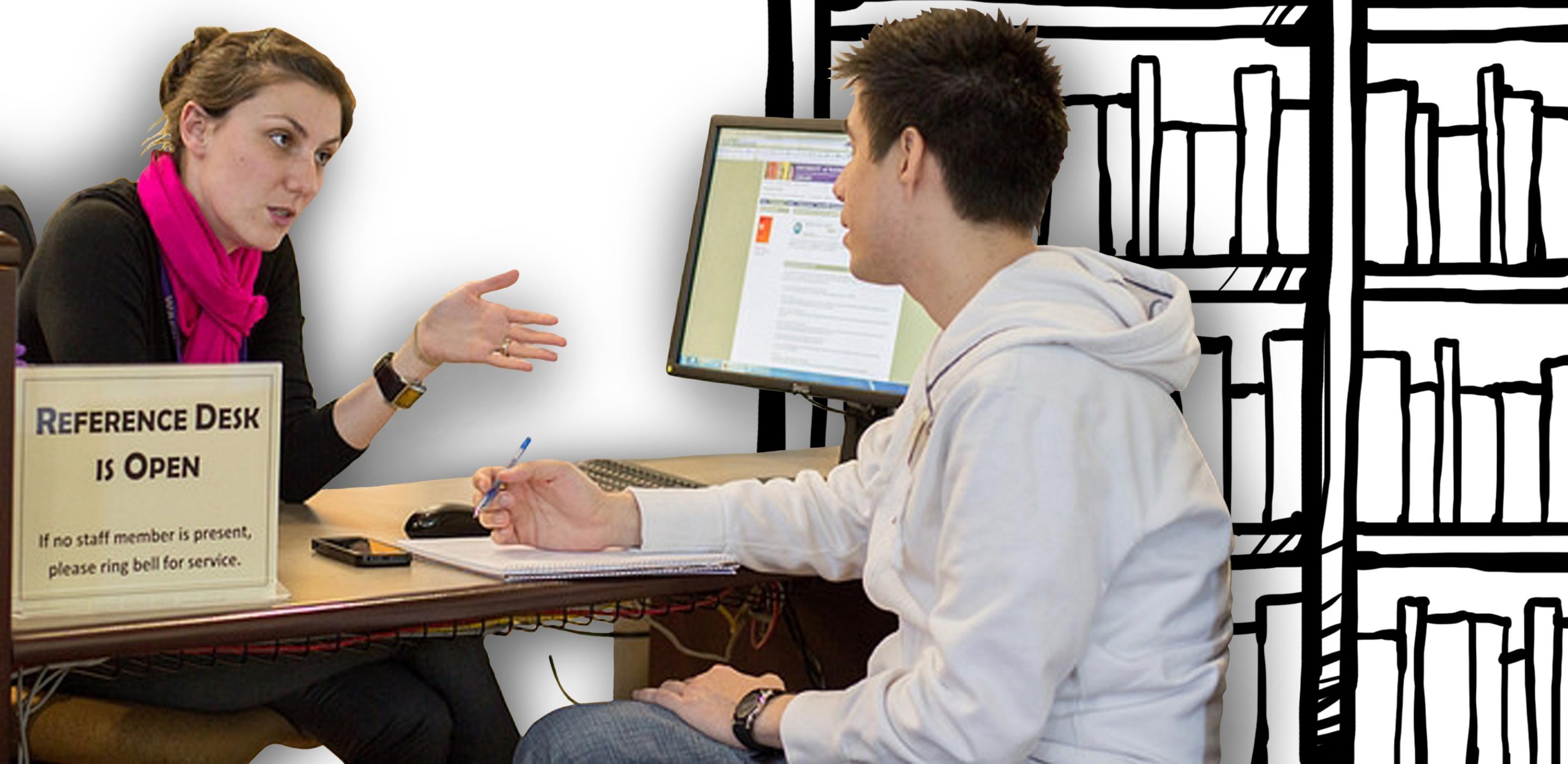


Maoria Maoria Maoria Maoria Maoria Maoria Maoria Maoria Maoria Maoria Maoria Maoria Maoria Maoria Maoria Maoria Maoria Maoria Maoria Maoria Maoria Maoria Maoria Maoria Maoria Maoria Maoria Maoria Maoria Maoria Maoria Maoria Maoria Maoria Maoria Maoria Maoria Maoria Maoria Maoria Maoria Maoria 


\section{What would we change?}

- Teach project planning

- Emphasize research in pre-writing phase

- Schedule individual appointments in the classroom

- Change activities for class visits 2 \& 3
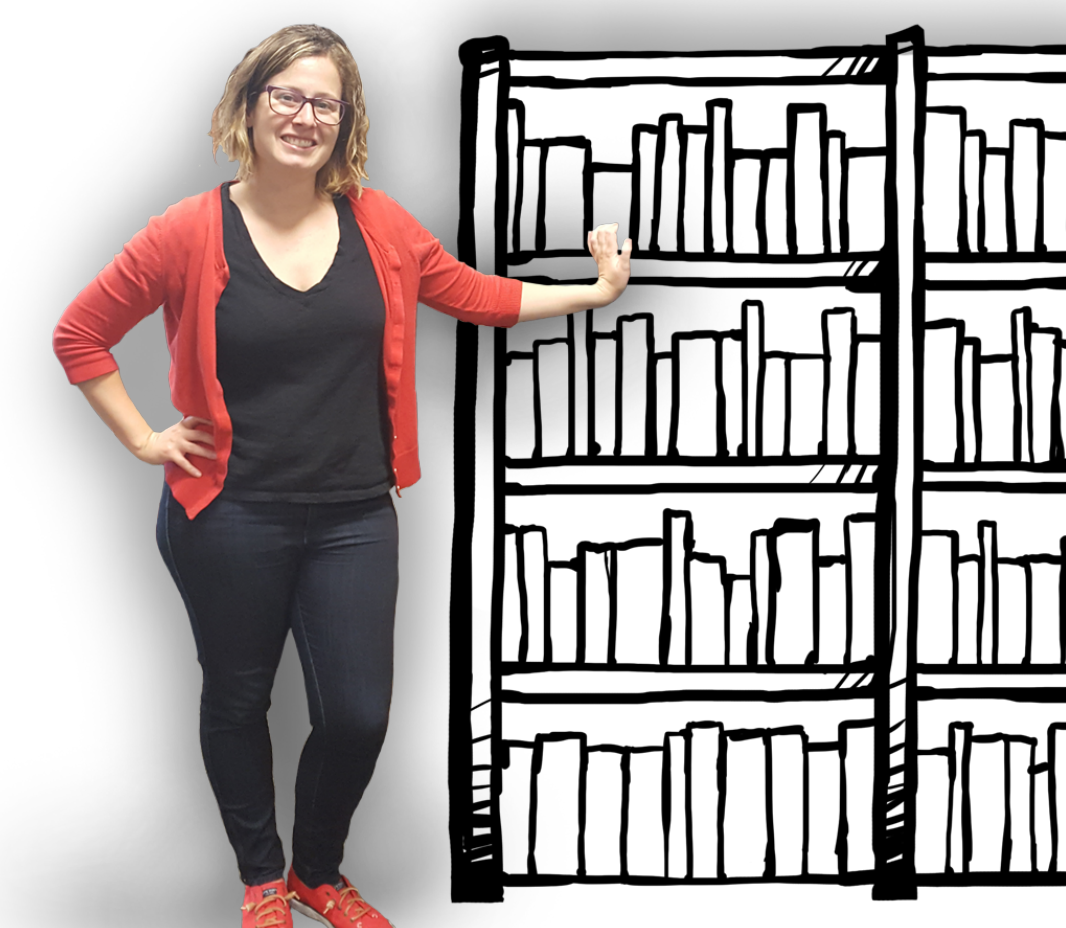
Implications for a similar partnership in your classroom

- Co-teaching empowers students to engage in self-regulated learning

- Students begin to see the library as a place to seek research instruction

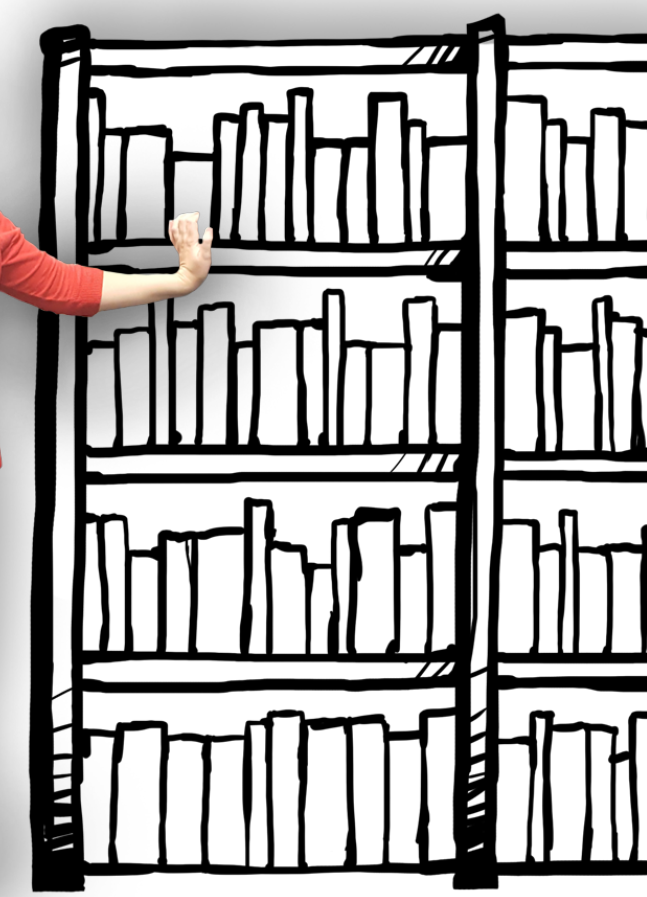


7 ways to re-create this partnership in your own classroom:

1. Plan early.

2. Agree on learning goals.

3. Look for good chemistry.

4. Repeat. Repeat. Repeat.

5. Chunk content.

6. Stay active.

7. Conduct a post-mortem.

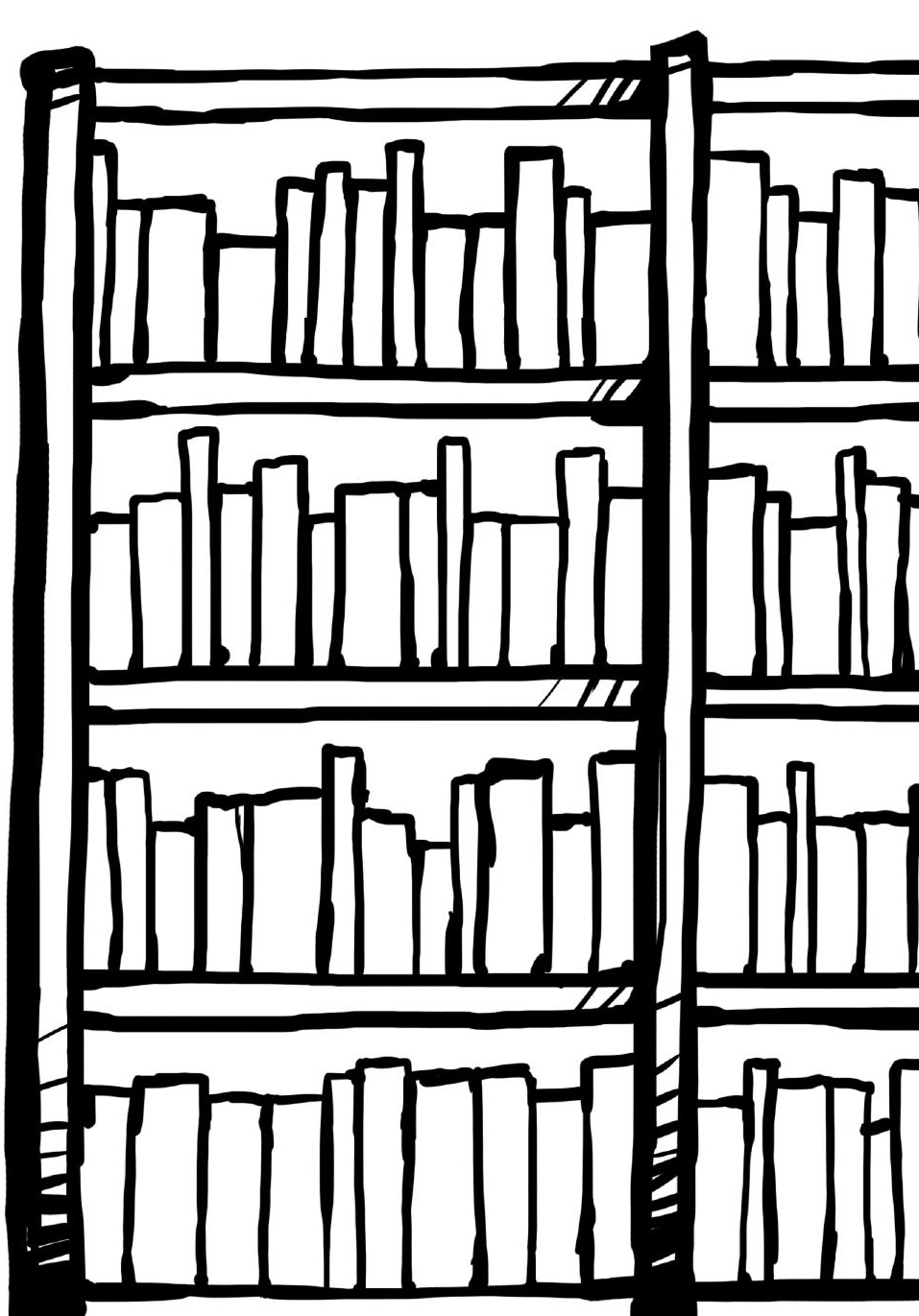




$$
\nabla
$$

